\title{
The singular epidemiology of HPV infection among French Guianese women with normal cytology
}

\author{
Antoine Adenis ${ }^{1}$, Valentin Dufit ${ }^{1}$, Maylis Douine ${ }^{1}$, Fatiha Najioullah ${ }^{2}$, Vincent Molinie ${ }^{3}$, Dominique Catherine ${ }^{3}$, \\ Odile Kilié ${ }^{2}$, Nadia Thomas ${ }^{4}$, Jean Luc Deshayes ${ }^{5}$, Paul Brousse ${ }^{6}$, Hatem Ben Amor ${ }^{6}$, Remy Pignoux ${ }^{6}$, Gabriel Carles ${ }^{7}$, \\ Claire Grenier ${ }^{6}$, Vincent Lacoste ${ }^{8}$, Raymond Cesaire ${ }^{2}$ and Mathieu Nacher ${ }^{1 *}$
}

\begin{abstract}
Background: In French Guiana, cervical cancer is the second most frequent cancer in females. The objective of the present study was to describe the prevalence of HPV infections in women with normal cervical cytology living in the remote villages of French Guiana.

Methods: Before the study, the study team communicated in the remote villages on the importance of screening. All women from the target population were offered to participate. They signed informed consent during inclusion and then had a concomitant HPV-test and cervical smear. Only women with normal cytology and a good quality smear were analyzed. The detection of HPV-DNA was performed using the GREINER-BIO-ONE kit.

Results: Overall, $27.2 \%$ of women with normal cervical cytology had a positive HPV-test. There was a U-shaped evolution of prevalence with women over 50 years having the highest HPV prevalence, followed by the 20 to 29 years group. The most prevalent HPV genotypes were HPV 53(3.52\%), 68(3.33\%), 52(2.59\%), $31(2.22 \%)$ and 16 (1. 85\%). The proportion of HPV 16 among HPV-infected women was $6.8 \%$.
\end{abstract}

Conclusions: HPV prevalence in cytologically normal women was very high. The most prevalent genotypes were very different from what is usually described in the world, and notably in South America.

Keywords: Human papillomavirus, Genotype, Normal cytology, Prevalence, French Guiana

\section{Background}

Cervical cancer is caused by the Human Papilloma Virus. In French Guiana, the standardized incidence rate of cervical cancer is 30.3 per 100,000 women. It is the second most frequent cancer in females [1] and causes significant mortality [2]. These figures show that the epidemiology of cervical cancer in French Guiana, a French territory, is South American rather than French [3].

French Guiana is covered by primary forest and has a population of 240,000 inhabitants, mostly living along the coastline. However, part of the population lives in the interior of French Guiana and has reduced access to care when compared to persons living in the main cities.

\footnotetext{
* Correspondence: mathieu.nacher@ch-cayenne.fr

${ }^{1}$ Centre d'Investigation Clinique Antilles-Guyane, CIC INSERM 1424, Centre hospitalier de Cayenne, Rue des flamboyants, 97300 Cayenne, French Guiana Full list of author information is available at the end of the article
}

Studies have shown that persons start their sexual life early and have a greater number of sex partners than reported in mainland France. This presumably favors the sexual transmission of this virus $[4,5]$.

Vaccination against HPV is now recommended in France, and thus in French Guiana (bivalent or tetravalent vaccines have been commercialized since 2007) [6]. The opportunistic screening of women aged 25-65 years is recommended using cytological examination of cervicovaginal smears. In France, the HPV test is only reimbursed when cytological examination reveals ASCUS lesions [7].

In French Guiana, efforts to conduct organized screening have been implemented in coastal areas, but not in the interior where isolation and lack of staff make it more difficult. Throughout the world, a number of studies have described the prevalence and risk factors of HPV in cytologically normal women [8-12]. Several 
studies in this particular subgroup have been pooled and have allowed to publish a meta analysis summarizing the findings and the marked regional differences regarding prevalence and the most prevalent genotypes [13, 14]. Chronic cervical inflammation may impair local immunity and influence the relative penetrance of other HPV genotypes than HPV 16 [13]. This target population may thus be more suitable for global comparisons.

In French Guiana, weconducted a study between 2012 and 2014 to determine the prevalence of HPV infection in women aged 20-65 living in the remote villages along the border rivers between French Guiana and Suriname or French Guiana and Brazil. Women had both a cervical smear and an HPV test. The objective of the present report was thus to describe the prevalence and risk factors of HPV infections in women with normal cervical cytology, and to compare these results with other regions of the world.

\section{Methods}

\section{Study population}

The cross sectional study took place between December 2012 and September 2014. The study population consisted of women aged 20-65 years having previously had sexual activity living in the remote villages on the Maroni and Oyapock rivers. Among these women only those with normal cervical cytology (Bethesda 2001 criteria) were included in the analysis.

Women with a history hysterectomy, pregnant women (>3 months pregnant) were not included. Women with abnormal cervical cytology were not included. Smears of insufficient quality (with an absence of endocervical cells) were excluded.

The detection of HPV DNA was performed using the GREINER-BIO-ONE kit at the Virology laboratory in Fort de France University Hospital. This kit allows the identification of high risk HPV genotypes 16, 18, 31, 33, $35,39,45,51,52,53,56,58,59,66,68,70,73,82$ and low risk genotypes $6,11,40,42,43,44,55$.

\section{Data collection}

A short questionnaire was used to collect socio economic and demographic data, and the gynecological and obstetrical history. Vaccines against HPV being theoretically available since 2006 (tetravalent) or 2007(bivalent), all women were asked if they had been vaccinated against HPV.

\section{Study conduct}

A study coordinator first went to the study sites to meet the key opinion leaders, local authorities (administrative and traditional). Communication was performed in all villages in order to sensitize the local populations about the public health problem of cervical cancer before beginning the inclusion of study patients. Health center workers were also informed and the logistical conditions of the health centers were assessed to ensure that the study was feasible. Three weeks before the research started, radio messages were aired several times a day in local languages informing the population about when the study would take place in the village. A study coordinator first went to the study sites to meet the key opinion leaders, local authorities. Three weeks before the research started, radio messages were airedseveral times a day in local languages informing the population about when the study would take place in the village. When the study team arrived, persons wishing to do an HPV test and cervical cytology came to the health center. The project was explained to them, the questionnaire was then filled and samples were taken using the ThinPrep ${ }^{\circ}$ kits. Samples were stored in a cooler until the end of the mission. The samples were then sent to Fort de France Hospital's Virology laboratory, in Martinique, where an automated method was used for DNA extraction and genotyping. Sample DNA extraction was performed using a minimum of $2 \mathrm{ml}$ in a liquid phase, followed by PCR for amplification, and genotyping using a kit that could discriminate between 20 genotypes, (HR and potentially oncogenic genotypes) and identify multiple infections.

When the HPV test was positive and when cytology was negative, a gynecological follow up was recommended to verify if HPV positivity had disappeared or if cytological lesions had appeared.

\section{Ethical and regulatory aspects}

For study participants, the HPV test and cytology were free of charge. All included subjects gave written informed consent to participate in the study and for the publication of its results. Regulatory and ethical approval were given by the Comite d'Evaluation Ethique de l'Inserm (CEEI), approval n ${ }^{\circ} 12-064$; the Comité Consultatif sur le Traitement de l'Information en matière de Recherche dans le domaine de la Santé (CCTIRS), $\mathrm{n}^{\circ}$ 12.310; and the Commission Nationale de l'Informatique et des Libertés (CNIL), n 912,459.

\section{Data analysis}

Prevalence was obtained by dividing the number of women with normal cytology infected by at least one HPV genotype (high grade or low grade) by the total number of women with normal cervical cytology. For specific genotypes, prevalence was obtained by the number of women infected with normal cytology by that specific genotype by the total number of women with normal cervical cytology. The direct standardization method was used to obtain the standardized HPV prevalence (using the world population as a reference 
population). The sample size required to detect a $30 \%$ prevalence with a $5 \%$ margin of error and a $95 \%$ confidence interval and an estimated population of 10,000 would be 313 persons, a figure which was exceeded.

Risk factors associated with HPV prevalence were determined using Generalized Linear Models using the log link and Poisson family. The Pearson goodness of fit test was used. The data was analyzed using STATA 13 software (College Station, Texas, USA).

\section{Results}

Overall, a total of 643 women were included, of which 540 women had normal cytology. Sexual relations generally started at a young age, with $19.1 \%$ percent of the surveyed women having had their first sexual relation before the age of 15 years.

A large proportion $(N=147,27.2 \%)$ of women with normal cytology had a positive HPV test. Table one shows a high HPV prevalence notably for the high risk viruses. The overall age-standardized prevalence was 28.9\%. Table 1 shows there was a $U$ shaped evolution of overall HPV prevalence by age and of high-risk-HPV prevalence by age, with women over 50 years of age at highest risk for HPV (40.8\%), followed by the 20 to 29 years group (27.5\%). Speaking Maroon languages was associated with a greater HPV prevalence, whereas speaking Portuguese was associated with a lower HPV prevalence. Other risk factors such as the number of sex partners, age at first sex, contraception use, parity, education, or smoking were not significantly associated with differences in HPV prevalence. None of the women declared receiving the HPV vaccine.

Table 2 shows that HPV 53 and 68 were the 2 most frequent high risk viruses. HPV16 was the 5 th most frequent genotype in women of all ages with normal cervical cytology. However, it was the most frequent in women aged 30-39 years with normal cervical cytology. It seemed less frequent in women aged over 40 years. Overall, the prevalence of HPV 16 or 18 exceeded $3 \%$ (95\% CI $2.1 \%-5.4 \%)$ of tested women with normal cervical cytology. Among women with normal cytology with any (low and high risk) HPV infection, the proportion of women infected with HPV 16 was $6.8 \%$ (95\% CI $3.3 \%-12.1 \%)$. Among women with normal cytology with high risk HPV infection, the proportion of women infected with HPV 16 was $8.7 \%$ (95\% CI 4.2\%-15.4\%).

Overall, 115 women $(21.3 \%)$ had single HPV infections, 23 (4.3\%) had double infections, and 9 (1.7\%) had 3 or more different HPV genotypes. Having more than one HPV genotype was more frequent in women over 50 years of age $(11 / 20)$ relative to those $<=50(21 / 95)$ (crude OR $=2.5$ (95\% CI 1-6.4), $p=0.037$.

Table 3 shows multiple regression analysis models predicting HPV positivity in women with normal
Table 1 HPV prevalence in women with normal cervical cytology living in the remote areas of French Guiana

\begin{tabular}{|c|c|c|c|c|c|}
\hline & \multirow[b]{2}{*}{$\mathrm{N}$} & \multirow[b]{2}{*}{ Overall \% } & \multicolumn{3}{|c|}{$\begin{array}{l}\text { Proportion of women } \\
\text { positive for HPV }\end{array}$} \\
\hline & & & $\%$ any HPV & $\% \mathrm{HR}$ & $\% L R$ \\
\hline Total & 540 & 100.0 & 27.2 & 17.9 & 8.7 \\
\hline \multicolumn{6}{|l|}{ Age (years) } \\
\hline $20-29$ & 142 & 26.3 & 27.5 & 21.8 & 7.0 \\
\hline $30-39$ & 197 & 36.5 & 25.9 & 18.8 & 9.1 \\
\hline $40-49$ & 125 & 23.1 & 20.8 & 16.0 & 7.2 \\
\hline $50-64$ & 76 & 14.1 & 40.8 & 35.5 & 13.2 \\
\hline \multicolumn{6}{|l|}{ Education } \\
\hline Never & 183 & 33.9 & 32.8 & 27.3 & 10.9 \\
\hline Low & 173 & 32.0 & 26.0 & 19.1 & 9.2 \\
\hline Intermediate and high & 181 & 33.5 & 21.5 & 16.6 & 5.5 \\
\hline Missing & 3 & 0.6 & 100.0 & 66.7 & 33.3 \\
\hline \multicolumn{6}{|l|}{ Native language } \\
\hline Maroon languages & 222 & 41.1 & 31.1 & 24.8 & 9.5 \\
\hline Amerindian languages & 177 & 32.8 & 26.6 & 20.9 & 9.0 \\
\hline Portugueuse & 98 & 18.1 & 20.4 & 16.3 & 6.1 \\
\hline Others & 43 & 8.0 & 25.6 & 16.3 & 9.3 \\
\hline \multicolumn{6}{|l|}{$\begin{array}{l}\text { Age at first sexual } \\
\text { intercourse }\end{array}$} \\
\hline$<15$ & 103 & 19.1 & 25.2 & 20.4 & 5.8 \\
\hline $15-17$ & 191 & 35.4 & 24.1 & 18.8 & 6.8 \\
\hline$>=18$ & 73 & 13.5 & 27.4 & 21.9 & 12.3 \\
\hline Missing & 173 & 32.0 & 31.8 & 24.3 & 11.0 \\
\hline \multicolumn{6}{|c|}{$\begin{array}{l}\text { Number of sexual partners } \\
\text { in previous year }\end{array}$} \\
\hline 0 & 38 & 7.0 & 36.8 & 34.2 & 15.8 \\
\hline 1 & 321 & 59.4 & 25.5 & 19.6 & 7.5 \\
\hline$>=2$ & 61 & 11.3 & 26.2 & 23.0 & 6.6 \\
\hline Missing & 120 & 22.2 & 29.2 & 20.8 & 10.8 \\
\hline \multicolumn{6}{|l|}{ Parity } \\
\hline $0-1$ & 89 & 16.5 & 29.2 & 27.0 & 4.5 \\
\hline $2-3$ & 162 & 30.0 & 22.8 & 16.0 & 9.9 \\
\hline $4-5$ & 131 & 24.3 & 26.7 & 22.1 & 6.1 \\
\hline$>5$ & 158 & 29.3 & 31.0 & 22.8 & 12.0 \\
\hline \multicolumn{6}{|l|}{ Contraceptives } \\
\hline Never & 362 & 67.0 & 26.5 & 21.8 & 8.0 \\
\hline Oral & 86 & 15.9 & 32.6 & 24.4 & 9.3 \\
\hline Others & 92 & 17.0 & 25.0 & 16.3 & 10.9 \\
\hline \multicolumn{6}{|l|}{ Smoking } \\
\hline Yes & 29 & 5.4 & 27.6 & 13.8 & 13.8 \\
\hline No & 511 & 94.6 & 27.2 & 21.7 & 8.4 \\
\hline
\end{tabular}


Table 2 Prevalence of different HPV genotypes in women with normal cervical cytology living in remote areas of French Guiana

\begin{tabular}{|c|c|c|c|c|c|}
\hline & $\begin{array}{l}\text { Age }<30 \\
\text { years } \\
(n=142)\end{array}$ & $\begin{array}{l}\text { Age } 30-39 \\
\text { years } \\
(n=197)\end{array}$ & $\begin{array}{l}\text { Age }>=40 \\
\text { years } \\
(n=201)\end{array}$ & $\begin{array}{l}\text { All ages } \\
(n=540)\end{array}$ & Prevalence \\
\hline & No & No & No & No & $\%$ \\
\hline \multicolumn{6}{|c|}{ HPV HR type } \\
\hline 53 & 6 & 5 & 8 & 19 & 3.52 \\
\hline 68 & 3 & 4 & 11 & 18 & 3.33 \\
\hline 52 & 5 & 2 & 7 & 14 & 2.59 \\
\hline 31 & 4 & 3 & 5 & 12 & 2.22 \\
\hline 16 & 3 & 6 & 1 & 10 & 1.85 \\
\hline 56 & 5 & 2 & 3 & 10 & 1.85 \\
\hline 18 & 1 & 3 & 5 & 9 & 1.67 \\
\hline 51 & 1 & 5 & 3 & 9 & 1.67 \\
\hline 58 & 4 & 2 & 1 & 7 & 1.30 \\
\hline 39 & 2 & 2 & 3 & 7 & 1.30 \\
\hline 70 & 0 & 3 & 4 & 7 & 1.30 \\
\hline 45 & 0 & 3 & 2 & 5 & 0.93 \\
\hline 66 & 2 & 2 & 0 & 4 & 0.74 \\
\hline 35 & 0 & 1 & 2 & 3 & 0.56 \\
\hline 73 & 2 & 0 & 1 & 3 & 0.56 \\
\hline 82 & 1 & 1 & 0 & 2 & 0.37 \\
\hline 33 & 0 & 0 & 1 & 1 & 0.19 \\
\hline 59 & 0 & 0 & 1 & 1 & 0.19 \\
\hline \multicolumn{6}{|c|}{ HPV LR type } \\
\hline 44 / 55 & 3 & 9 & 12 & 24 & 4.44 \\
\hline 42 & 3 & 4 & 3 & 10 & 1.85 \\
\hline 6 & 3 & 4 & 0 & 7 & 1.30 \\
\hline 40 & 1 & 1 & 3 & 5 & 0.93 \\
\hline 43 & 0 & 0 & 2 & 2 & 0.37 \\
\hline 11 & 0 & 0 & 1 & 1 & 0.19 \\
\hline
\end{tabular}

cervical cytology. No variables significantly predicted HPV positivity.

\section{Discussion}

The apparent variation in the relative importance of different HPV genotypes requires further research including studies from regions where data is lacking, and reanalyzing existing data to better understand the observed patterns. [13] The published studies included in the pooled analysis and in the metaanalysis used the international cancer research association standard methodology for HPV prevalence surveys. Our sampling design was tailored to fit the logistical constraints of the remote villages in French Guiana. This may have introduced some differences in the prevalence estimations, but it seems unlikely that the relative frequency of different genotypes would be affected. [13].

Overall, the observed crude and standardized (28.9\%) HPV prevalence among cytologically normal women in this French territory was among the highest reported in the world. It was notably much higher than in other areas of South America (standardized prevalence = 14.3\%). However, the published reviews in the group of cytologically normal women in South America $[13,14]$ did not involve women living in the Amazon basin which is ethnically and socioeconomically different from Argentina (standardized prevalence $=16.3 \%)[15]$, Chile (standardized prevalence $=11.9 \%$ ) [16], or Colombia (standardized prevalence $=13.9 \%$ ) [17]. Indeed a recent study in the Brazilian State of Amazonas showed a very high HPV prevalence (crude prevalence in women with and without cytological anomalies $=39.7 \%$ ) [18]. It is also worth noting that the mean age in women from Amazonas was 1.6 years younger than women from French Guiana. When looking at the most frequent genotypes, the results from rural French Guiana were also very different from pooled results from different areas of the world. HPV 16 was only found in $6.8 \%$ of HPV-positive women with normal cervical cytology, whereas it has been reported to be around 21.4\% in South America [13], 13.7\% in Mexico [19], and 9.8\% in Costa Rica [20], and $25.5 \%$ in Europe, $24.1 \%$ in Canada [21], and $31.2 \%$ in the USA [13, 22]. Thus, the prevalence of HPV 16 in French Guiana was lower than but close to the prevalence in Mexico and Costa Rica. In French Guiana, HPV 16 was overall the 5th most frequent genotype whereas HPV 53 and HPV 68 were the 2 most frequent, which is a singularity when compared to other regions of the world where HPV 16 is the most frequent followed by HPV 58. HPV 31 was the 4th most frequent genotype in our study $(2.2 \%$ of women with normal cytology) and, globally, it is the 3rd most common genotype $(0.7 \%$ of all women with normal cytology). In rural Amazonas, where HPV prevalence was reported to be very high [18], the most frequent HPV genotypes were HPV 31, 68 and 53 in Macuxi and Wapishana women (which is similar as in our study), whereas for the Yanomani women, it was HPV 16, 31 and 18. However, this study included women with abnormal cytology and thus the comparison may not be appropriate [18].

These differences may reflect epidemiologic differences in transmission chains in these remote areas populated with ethnically homogenous populations with little admixture. A possible explanation for these differences in small isolated populations could be the founder effect, were a few individuals have spread these HPV genotypes. Immunologic differences between these ethnic groups (HLA allele frequencies in Amerindians versus Maroons for example [23]) could also influence the observed patterns of HPV genotypes. [24-27] 
Table 3 Generalized linear model analyzing potential risk factors for HPV infection in women with normal cervical cytology living in the remote areas of French Guiana

\begin{tabular}{|c|c|c|c|c|c|c|}
\hline & \multicolumn{2}{|c|}{ Positive for HPV detection } & \multicolumn{2}{|c|}{ Positive for HPV HR type } & \multicolumn{2}{|c|}{ Positive for HPV LR type } \\
\hline & No & Prevalence ratio $^{\mathrm{a}}$ & No & Prevalence ratio $^{a}$ & No & Prevalence ratio ${ }^{a}$ \\
\hline \multicolumn{7}{|l|}{ Age (years) } \\
\hline $20-29$ & 39 & $1.6(0.7-3.4)$ & 31 & $1.6(0.7-3.7)$ & 10 & $1.4(0.3-5.3)$ \\
\hline $30-39$ & 51 & $1.3(0.6-2.5)$ & 37 & $1.4(0.6-3.1)$ & 18 & $1.1(0.3-3.2)$ \\
\hline $40-49$ & 26 & 1 (reference) & 20 & 1 (reference) & 9 & 1 (reference) \\
\hline $50-64$ & 31 & $1.9(0.9-4.5)$ & 27 & $2(0.8-5.2)$ & 10 & $1.6(0.4-7.2)$ \\
\hline \multicolumn{7}{|l|}{ Education } \\
\hline Never & 60 & 1 (reference) & 50 & 1 (reference) & 20 & 1 (reference) \\
\hline Low & 45 & $1(0.5-2.3)$ & 33 & $1(0.5-2)$ & 16 & $0.8(0.3-2.6)$ \\
\hline Intermediate and high & 39 & $0.7(0.4-1.5)$ & 30 & $0.7(0.3-1.6)$ & 10 & $0.4(0.1-1.6)$ \\
\hline \multicolumn{7}{|l|}{ Native language } \\
\hline Maroon languages & 69 & $1(0.5-2.1)$ & 55 & $0.9(0.4-2)$ & 21 & $0.9(0.2-3.7)$ \\
\hline Amerindian languages & 47 & $1.1(0.5-2.3)$ & 37 & $1.1(0.5-2.4)$ & 16 & $1.3(0.3-4.6)$ \\
\hline Portugueuse & 20 & 1 (reference) & 16 & 1 (reference) & 6 & 1 (reference) \\
\hline Others & 11 & $1.2(0.5-2.8)$ & 7 & $0.7(0.3-1.6)$ & 4 & $2.4(0.6-9.7)$ \\
\hline \multicolumn{7}{|c|}{ Age at first sexual intercourse } \\
\hline$<15$ & 26 & 1 (reference) & 21 & 1 (reference) & 6 & 1 (reference) \\
\hline $15-17$ & 46 & $1.0(0.6-1.8)$ & 36 & $0.9(0.5-1.6)$ & 13 & $1.3(0.5-3.5)$ \\
\hline$>=18$ & 20 & $1.2(0.6-2.6)$ & 16 & $1.1(0.5-2.1)$ & 9 & $2.8(0.9-9)$ \\
\hline \multicolumn{7}{|c|}{ Number of sexual partners in previous year } \\
\hline 0 & 14 & 1 (reference) & 13 & 1 (reference) & 6 & 1 (reference) \\
\hline 1 & 82 & $0.8(0.4-1.9)$ & 63 & $0.6(0.3-1.5)$ & 24 & $0.8(0.2-3.3)$ \\
\hline$>=2$ & 16 & $1.1(0.4-2.7)$ & 14 & $0.9(0.3-2.5)$ & 4 & $1.3(0.2-7)$ \\
\hline \multicolumn{7}{|l|}{ Parity } \\
\hline $0-1$ & 26 & 1 (reference) & 24 & 1 (reference) & 4 & 1 (reference) \\
\hline $2-3$ & 37 & $0.9(0.4-1.7)$ & 26 & $0.8(0.4-1.6)$ & 16 & $1.4(0.3-5.6)$ \\
\hline $4-5$ & 35 & $1.2(0.6-2.4)$ & 29 & $1(0.5-2.1)$ & 8 & $2(0.5-8.5)$ \\
\hline$>5$ & 49 & $1.3(0.6-2.7)$ & 36 & $0.9(0.4-2)$ & 19 & $2.6(0.5-12.4)$ \\
\hline \multicolumn{7}{|l|}{ Contraceptives } \\
\hline Never & 96 & 1 (reference) & 79 & 1 (reference) & 29 & 1 (reference) \\
\hline Oral & 28 & $1.1(0.6-2.1)$ & 21 & $1.1(0.5-2.2)$ & 8 & $1(0.3-3.1)$ \\
\hline Others & 23 & $0.8(0.4-1.7)$ & 15 & $0.6(0.2-1.4)$ & 10 & $1.6(0.5-4.5)$ \\
\hline \multicolumn{7}{|l|}{ Smoking } \\
\hline No & 139 & 1 (reference) & 111 & 1 (reference) & 43 & 1 (reference) \\
\hline Yes & 8 & $0.7(0.3-1.9)$ & 4 & $2.1(0.5-9.3)$ & 4 & $0.2(0.1-0.9)$ \\
\hline
\end{tabular}

${ }^{\mathrm{a} G L M}$ using the log link and Poisson family. Goodness of fit Pearson test $>0.9$ for all models

Further studies should however test this hypothesis. As observed elsewhere [14], there was a U-shaped evolution of HPV prevalence with women over 50 years of age having the highest HPV prevalence, and also being more likely to be infected by more than one HPV genotype. However, given the early start of sexual life in this region, it is possible that HPV prevalence is also high in women under twenty years of age, who were not surveyed here.

The originality of this epidemiologic situation may result from the very singular situation of the isolated populations: different ancestral origins of the Maroon and Amerindian populations living in adjacent villages, with early sexual debut, rare sexual encounters between 
ethnic groups, different immunological susceptibilities, and different pools of HPV viruses. These results reemphasize [28] the potential interest of primary screening using HPV testing in this region where over a quarter of HPV positive women have normal smears and harbor high grade HPV genotypes. This however requires authorities to expand reimbursement to all targeted women and not only those with abnormal cytology, as is presently the case. The main HPV genotypes circulating also suggest that vaccination coverage, which is presently null, needs to be expanded. This implies operational aspects, and perhaps also suggests that the tetravalent vaccine should be replaced with the nonavalent HPV vaccine, which covers HPV $6,11,16,18,31,33,45,52$, and 58, because here HPV 52 was the third and HPV 31 the fourth most frequent high risk genotypes when HPV16 was fifth and HPV 18 seventh most common high risk genotypes.

\section{Conclusions}

HPV prevalence in cytologically normal women was very high. The most prevalent genotypes were different from what is usually described in the world, and notably in South America beyond the Amazon basin. In a region where cervical cancer is frequent, vaccination against HPV and screening of women are important, but they must be adapted to the local epidemiology and made affordable for the populations.

\section{Acknowledgements}

We wish to thank all study participants and the staff from the health centers of French Guiana.

\section{Funding}

The Study was funded by the European Regional Development Fund (FEDER) Presage number 30814. The funders had no role in study design, data collection and analysis, decision to publish, or preparation of the manuscript.

\section{Availability of data and materials}

The data can be made available upon request with the Commission Nationale Informatique et Libertés and Cayenne Hospital.

\section{Authors' contributions}

AA VD coordinated the study. FN, VM, DC, OK, VL, RC were involved in virological/cytological analyses and interpretation. MD, NT, JLD, PB, HBA, RP, GC, CG were involved in the study conduct. VD, MN, AA were involved in data analysis. MN was involved in drafting the manuscript, and amendments suggested by other coauthors. All authors read and approved the final manuscript.

\section{Competing interests}

The authors declare that they have no competing interests.

\section{Consent for publication}

Not applicable.

\section{Ethics approval and consent to participate}

Ethics approval for the study was received from: the Comité d'Evaluation Ethique de I'Inserm (CEEI), approval nº 12-064; the Comité Consultatif sur le Traitement de l'Information en matière de Recherche dans le domaine de la Santé (CCTIRS), nº 12.310; the Commission Nationale de l'Informatique et des
Libertés (CNIL), nº 912,459. All study participants gave informed consent to participate in the study.

\section{Publisher's Note}

Springer Nature remains neutral with regard to jurisdictional claims in published maps and institutional affiliations.

\section{Author details}

${ }^{1}$ Centre d'Investigation Clinique Antilles-Guyane, CIC INSERM 1424, Centre hospitalier de Cayenne, Rue des flamboyants, 97300 Cayenne, French Guiana. ${ }^{2}$ Laboratoire de Virologie, CHU de la Martinique, Fort de France, Martinique. ${ }^{3}$ Laboratoire d'anatomopathologie, CHU de la Martinique, Fort de France, Martinique. ${ }^{4}$ Service de Gynecologie Obstétrique, Centre hospitalier de Cayenne, Cayenne, French Guiana. ${ }^{5}$ AGDOC Association de Dépistage Organisé des Cancers de Guyane, Cayenne, French Guiana. ${ }^{6}$ Département des Centres délocalisés de prévention et de soins, Centre Hospitalier de Cayenne, 97300 Cayenne, French Guiana. ${ }^{7}$ Service de Gynecologie Obstétrique, Centre Hospitalier de l'Ouest Guyanais, Saint Laurent du Maroni, Cayenne, French Guiana. ${ }^{8}$ Laboratoire des interactions virus Hôtes, Institut Pasteur de la Guyane, Cayenne, French Guiana.

Received: 26 October 2016 Accepted: 9 March 2017

Published online: 24 March 2017

\section{References}

1. Roue T, Nacher M, Fior A, Plenet J, Belliardo S, et al. Cervical cancer incidence in French Guiana: South American. Int J Gynecol Cancer. 2012;22: 850-3.

2. Douine $M$, Roue $T$, Fior A, Adenis $A$, Thomas $N$, et al. Survival of patients with invasive cervical cancer in French Guiana, 2003-2008. Int J Gynaecol Obstet 2014:125:166-7.

3. Arrossi S, Sankaranarayanan R, Parkin DM. Incidence and mortality of cervical cancer in Latin America. Salud Publica Mex. 2003:45 (Suppl 3):S306-14.

4. van Melle A, Parriault MC, Basurko C, Jolivet A, Flamand C, et al. Knowledge, attitudes, behaviors, and practices differences regarding HIV in populations living along the Maroni river: particularities of operational interest for Amerindian and Maroon populations. AIDS Care. 2015;27:1112-7.

5. Ayhan G, Martin L, Levy-Loeb M, Thomas S, Euzet G, et al. Prevalence and risk factors of early onset of sexual intercourse in a random sample of a multiethnic adolescent population in French Guiana. AIDS Care. 2015;27:1025-30.

6. (ANSM) ANdSdMedPdS. Mise sur le marché du vaccin pour la prévention d'infections liées au virus papilloma; 2007

7. Has S. État des lieux et recommandations pour le dépistage du cancer du col de l'utérus en France. Paris; 2010. http://www.has-sante.fr/portail/jcms/c_ 1009772/fr/etat-des-lieux-et-recommandations-pour-le-depistage-du-cancerdu-col-de-l-uterus-en-france

8. de Roda Husman AM, Walboomers JM, Hopman E, Bleker OP, Helmerhorst TM, et al. HPV prevalence in cytomorphologically normal cervical scrapes of pregnant women as determined by PCR: the age-related pattern. J Med Virol. 1995:46:97-102.

9. Hildesheim A, Schiffman MH, Gravitt PE, Glass AG, Greer CE, et al. Persistence of type-specific human papillomavirus infection among cytologically normal women. J Infect Dis. 1994;169:235-40.

10. Kjaer SK, van den Brule AJ, Bock JE, Poll PA, Engholm G, et al. Determinants for genital human papillomavirus (HPV) infection in 1000 randomly chosen young Danish women with normal Pap smear: are there different risk profiles for oncogenic and nononcogenic HPV types? Cancer Epidemiol Biomark Prev. 1997:6:799-805.

11. Melkert PW, Hopman E, van den Brule AJ, Risse EK, van Diest PJ, et al. Prevalence of HPV in cytomorphologically normal cervical smears, as determined by the polymerase chain reaction, is age-dependent. Int J Cancer. 1993;53:919-23.

12. Wheeler CM, Parmenter CA, Hunt WC, Becker TM, Greer CE, et al. Determinants of genital human papillomavirus infection among cytologically normal women attending the University of New Mexico student health center. Sex Transm Dis. 1993;20:286-9.

13. Clifford GM, Gallus S, Herrero R, Munoz N, Snijders PJ, et al. Worldwide distribution of human papillomavirus types in cytologically normal women in the International Agency for Research on Cancer HPV prevalence surveys: a pooled analysis. Lancet. 2005;366:991-8. 
14. de Sanjose S, Diaz M, Castellsague X, Clifford G, Bruni L, et al. Worldwide prevalence and genotype distribution of cervical human papillomavirus DNA in women with normal cytology: a meta-analysis. Lancet Infect Dis. 2007;7:453-9.

15. Matos E, Loria D, Amestoy GM, Herrera L, Prince MA, et al. Prevalence of human papillomavirus infection among women in Concordia, Argentina: a population-based study. Sex Transm Dis. 2003;30:593-9.

16. Ferreccio C, Prado RB, Luzoro AV, Ampuero SL, Snijders PJ, et al. Populationbased prevalence and age distribution of human papillomavirus among women in Santiago, Chile. Cancer Epidemiol Biomark Prev. 2004;13:2271-6.

17. Molano M, Posso H, Weiderpass E, van den Brule AJ, Ronderos M, et al. Prevalence and determinants of HPV infection among Colombian women with normal cytology. Br J Cancer. 2002;87:324-33.

18. Fonseca AJ, Taeko D, Chaves TA, Amorim LD, Murari RS, Miranda AE, Chen Z, Burk RD, Ferreira LC, et al. HPV Infection and Cervical Screening in Socially Isolated Indigenous Women Inhabitants of the Amazonian Rainforest. PLoS One. 2015;10(7):e0133635. doi:10.1371/journal.pone.0133635. eCollection 2015.

19. Lazcano-Ponce E, Herrero R, Munoz N, Cruz A, Shah KV, et al. Epidemiology of HPV infection among Mexican women with normal cervical cytology. Int J Cancer. 2001;91:412-20.

20. Herrero RC, Castle PE, Schiffman M, et al. Epidemiologic profile of typespecific HPV infection and cervical neoplasia in Guanacaste, Costa Rica. J Infect Dis. 2005;191:1796-807.

21. Richardson HKG, Tellier $P$, et al. The natural history of type-specific human papillomavirus infections in female university students. Cancer Epidemiol Biomark Prev. 2003:12:485-90

22. Brown DRL, Legge D, Qadadri B. Distribution of human papillomavirus types in cervicovaginal washings from women evaluated in a sexually transmitted diseases clinic. Sex Transm Dis. 2002;29:763-8.

23. Fernandez-Vina MA, Gao XJ, Moraes ME, Moraes JR, Salatiel I, et al. Alleles at four HLA class II loci determined by oligonucleotide hybridization and their associations in five ethnic groups. Immunogenetics. 1991;34:299-312.

24. Allen M, Kalantari M, Ylitalo N, Pettersson B, Hagmar B, et al. HLA DQ-DR haplotype and susceptibility to cervical carcinoma: indications of increased risk for development of cervical carcinoma in individuals infected with HPV 18. Tissue Antigens. 1996:48:32-7.

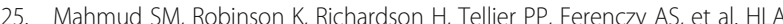
polymorphisms and cervical human Papillomavirus infection in a cohort of Montreal University students. J Infect Dis. 2007:196:82-90.

26. Maciag PC, Schlecht NF, Souza PS, Franco EL, Villa LL, et al. Major histocompatibility complex class II polymorphisms and risk of cervical cancer and human papillomavirus infection in Brazilian women. Cancer Epidemiol Biomark Prev. 2000;9:1183-91.

27. Metcalfe S, Roger M, Faucher MC, Coutlee F, Franco EL, et al. The association between human leukocyte antigen (HLA)-G polymorphisms and human papillomavirus (HPV) infection in Inuit women of northern Quebec. Hum Immunol. 2013;74:1610-5.

28. Sankaranarayanan R, Nene BM, Shastri SS, Jayant K, Muwonge R, et al. HPV screening for cervical cancer in rural India. N Engl J Med. 2009;360:1385-94.

\section{Submit your next manuscript to BioMed Central and we will help you at every step:}

- We accept pre-submission inquiries

- Our selector tool helps you to find the most relevant journal

- We provide round the clock customer support

- Convenient online submission

- Thorough peer review

- Inclusion in PubMed and all major indexing services

- Maximum visibility for your research

Submit your manuscript at www.biomedcentral.com/submit

) Biomed Central 